\title{
SPEECH-LANGUAGE THERAPY GIVEN TO KING GEORGE VI IN THE KING'S SPEECH MOVIE
}

\author{
Sa'adah $^{1}$, Hidayah Nor ${ }^{2}$ \\ State Islamic University of Sunan Ampel Surabaya ${ }^{1}$, IAIN Antasari Banjarmasin ${ }^{2}$ \\ aadah_bud1@yahoo.co.id'1, hidayahnor616@gmail.com²
}

\begin{abstract}
Language is a vital ability that one person should have in order to get connected with other people. One of the possible ways to build a good relationship with other people is speech, which cannot be separated from language. Unfortunately, not all people have the ability to manage their speech. Such problem called by psycholinguists as speech disorder is well captured in a true story movie entitled 'The King's Speech'. The main character in the movie, King George VI, has some difficulties to produce language especially when he has to perform speech in public. This research aimed to figure out the phenomena of speech disorder found in the movie. Using descriptive qualitative approach, the writer attempted to analyze the language productivity problems and the possible therapy given to solve the problems. The results show that King George VI has several speech disorder such as disfluency, articulation disorder and muteness. But, with some treatments, such as, muscle strengthening exercises, breathing strengthening exercises and phonetics therapy, he finally could reduce and overcome his speech disorder much better than the one he had beforehand.
\end{abstract}

Keywords: speech-language therapy; language disorder; language productivity

\section{INTRODUCTION}

Psycholinguistic is a study about language in relation to its speakers' psychological aspect (Aitchison, 2008; Fernandez \& Smith, 2011). Field (2004) added that "it provides insights into how we assemble our own speech and writing and how we understand that of others; into how we store and use vocabulary; into how we manage to acquire a language in the first place; and into how language can fail us. Psychological aspect has a big influence on making people able to use and understand language appropriately. When we are using language, we arefully responsible for producing language in a way that enables people to understandwhat we are trying to communicate. Such communication is usually done through a speech. In this case, speech is considered as the most profound ability that humans have with regard to their language production. However, not all human has the same ability to produce their language or to have smooth and good speech ability. Some are capable to express their ideas smoothly via their speech, but some are not that lucky. There are some people who find themselves in difficult circumstances to produce their language or to make speech. When they communicate, some of them may often find obstacles mentally or psychologically. It probably appears due to their brain condition or mental situation that may lead to what psychologist called as "speech disorder" or "language disorder". 
"Speech" refers to the actual sound of spoken language. It's the oral form of communicating. "Speech" is talking: using the muscles of the tongue, lips, jaw and vocal tract in a very precise and coordinated way to produce the recognizable sounds that make up language. Hence, when a person cannot produce language correctly, it means that he/she has a speech disorder. Speech disorder comprises of articulation disorder, disfluency or stuttering, voice disorder and muteness. These problems can be cured by some treatments such as muscle strengthening exercises, breathing exercises, speech fluency exercises, and sound improvement exercises (Caplan, 1992; Damico \& Martin, 2010; Kahn, 2016).

Such problem can be captured in a true story movie entitled 'The King's Speech'. It is a story about a real King of England long time ago who had to change his old brother to lead the empire. This movie has its magnet not only because it is based on a true story but also because it contains a problem that a king had in the past. Behind his great status, the King had a very vital problem in using language, a problem that an ideal king should have never had. He had no pride due to his speech impairment. The movie shows that speech disorder was really problematic to the King and had become an interesting topic since a long time ago. How King George VI, as the main character in the movie, cured his problem through speechlanguage therapy become an interesting issue. In this study, I focused on analyzing the King's language production, the strategies used in speech-language therapy and the process of how the King followed the therapy.

\section{RESEARCH METHODS}

This research was designed as a descriptive qualitative study. According to Baxter (cited in Litosseliti, 2010) the approach focuses on studying language in its own right. There are four keys in the approach: principle of variability, constructed and constructive nature of language, interpretative repertoire and combination of micro and macro analytical approaches. There are three stages of analyzing the qualitative data: familiarization and organization, coding and recording, and the last is summarizing. Having said so, the researcher analyzed the data through some stages. First, the researcher read and re-read the script of the movie as the source of the data. And then the researcher made some notes to organize the data. Second, the researcher coded the data step by step or re-arranged the data into categories based on the research problems. And the last step was summarizing. Through the stages, the researcher could finally describe the data in detail to find the answer of the stated research problems. 


\section{FINDINGS AND DISCUSSION}

\subsection{Language Productivity of King George VI}

King George VI had to face his fate as the King in that period. In order to fulfill his fate, he had to meet a big fear in the early period of his leadership. He had to deliver some important speech dealing with the English government. Delivering a speech for some normal and regular person like us is not a big issue. But, for such a higher status and hold a big responsibility as a King, giving speech was the most difficult thing for King George VI especially when he had a problem with speech disorder. It was not easy for the King to produce his language smoothly. The data found in the movie proved that King George VI (named as Bertie in the movie) had some speech disorders as follows.

\subsubsection{Disfluency and Articulation Disorder}

\section{Problem of frequent pauses, repeating word 'the' and adding consonant ' $k$ '}

When Bertie, the nickname of the King, had to deliver his speech for the very first time in front of the public through a microphone, it appeared that he had a problem with his speech. He become very nervous because he realized that his speech will be heard publicly by his English citizens. This moment not only arose his nervousness but also made his speech disorder came up to public. It was clearly heard by the people who happened to listen his speech:

Bertie: "I have received...from his Majesty...the... K-K-K... theKing... ek-ek-ekek....(silent)"

One of the ways to recognize someone who has a speech disorder is when he/she is talking. He/she will take frequent pause when talking. As seen in the data above, the blank space "..." in the sentence means the pauses. We can see that Bertie made frequent pauses before he finished one sentence/message. Not only that, repeating word appeared in the dialogue (I marked it with the bold form). Bertie repeated the word "the" twice in one sentence.

Other form of speech disorder that clearly seen in Berties' speech was the articulation disorder. There was consonant added, "K-K-K" before saying the word "King", and in the last part of the sentence "ek-ek-ek....". This could support my analysis that Bertie also had articulation disorder. Even though it was a short speech, it was enough to prove that the King or Bertie had speech disorder problems. 


\section{Problem of frequent pauses, repeating words 'are'/'she'/'if'/'he' and adding vowel 'a'}

Not only occurs in public situation, speech disorder also happens even in a private setting. Once in his private moment, Bertie had to tell a story to his children in a private room (Bertie's house). And the symptoms of speech disorder was obvious in the way he told the story to his children:

Bertie: "Penguins have wings which are..are shaped like herrings. And what made matters worse she... she sent him to the South Pole, which is an awfully long walk back if... if you can fly. So, when he reached the water, he..he dived in, through the depths, so fast that he was in Southampton Waters by lunchtime. And from there, he took the 2:30 to Weybridge, changed at Clapham Junction, asked $\mathbf{a} \ldots$ a... a passing mallard the way to Buckingham Palace, swam up The Thames, out through the plughole and gave the cook, Mama and Mrs. Whittaker quite a shock. Now when the... girls heard all the commotion, they ran to the kitchen, where they gave him a...a good scrub, a mackerel and a kiss. And as they kissed him... guess what he turned into?"

In such situation, Bertie was able to say a lot of more words and sentences than he said in the first data. In spite of the different situation, I did not find any significant differences between the two situations: public and private. I still recognized the blank space "..." indicating that his speech disorder was still obviously appearing. In this long version dialogue, we can see a lot of pauses and repeated words showing him as a stammerer (a person with stuttering disorder). There are words such as "are", "she", "if", and "he" that he repeatedly said in his story. Meanwhile, articulation disorder is also represented in here by the repeated vowel added of "a".

\section{Problem of adding extra sounds 'uhm'/'ugh'/'akh', repeating words 'then'/'if', producing long pauses and consonants added ' $w$ '/' $k$ '/' $i$ '}

Bertie also found some obstacles when he had to talk with someone he met for the first time. The script below proves that Bertie was very much burdened with his speech disorder. He looked nervous and could not speak fluently to answer his therapist's questions, named Lionel.

Bertie : "Uhm.... ugh... w-waiting for me to...k...kk... commence a conversation, one can w-wait arather long wait"

Lionel : "Oh yeah. Do you know any jokes?"

Bertie : "Akh... ugh... timing isn't my strong suit..."

Bertie : "I....I prefer Doctor."

Lionel : "I prefer Lionel. What'll I call you?"

Bertie : "Your royal highness....then...then Sir after that."

Bertie : "If a...ifwe were equal I wouldn't...be here. I'd be at...home with my wife. And no one would...give a damn. (Taking cigarette and ready to smoke)"

Bertie : "One offff...my many faults."

Bertie : "So I...'ve been told. I...I can’t remember not doing it." 
Bertie : "Stop a..stop calling me that."

The data shows other signs of disfluency or stuttering that Bertie had. The words which are in bold; "Uhm", "Ugh", and "Akh" are extra sounds and words. The bold words are actually meaningless. A normal speaker will not say meaningless words when they are talking. Other characteristics of disfluency/stuttering that came up in here are the pauses mode, the repeated words such as "then" and "if".

But, what makes me interested in the third data is, I found other characteristic of disfluency. The word "of-fff" with adding triple "f" in the utterance represented that Bertie produced a long voice of the word "of". Besides disinfluency, articulation disorder also appeared in Bertie's utteranceswhen he repeatedly added consonant sounds such as "w", "k" and vocal sounds "a" and "ip".

Another worst type of speech disorder I found in the data is the muteness. It was quite often during the conversation with Lionel, Bertie just kept silent and did not respond anything to Lionel's questions.

\section{Problem of frequent pauses and adding consonant ' $p$ '}

The dialogue below was in the scene when Bertie had to give a Christmas greeting to his citizens as a command from his father. In this occasion, Bertie had to deliver the greeting through radio.

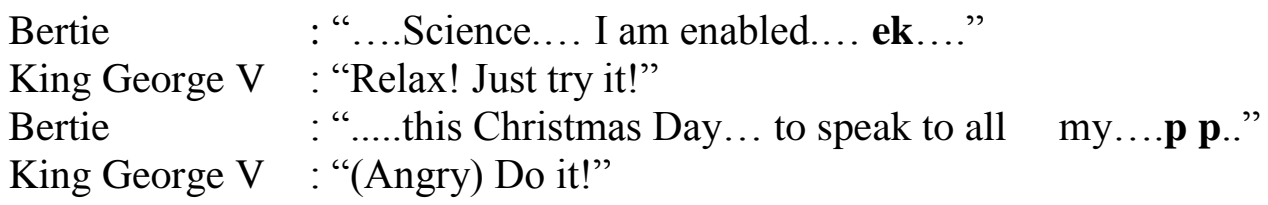

The fourth data showed how bad Bertie's speech disorder was. It always appeared worse when he had to give a speech in front of public. Pausing mode was longer than before (previous script) and adding consonant "p" existed again in the dialogue, even though it was only a short sentence. Stuttering made Bertie difficult to finish reading a full text, but not a sentence.

\section{Problem of vowel adding ' $i$ ' and words repeating 'are you'}

Bertie still found some difficulties to speak with other people, be it in the first time encounter or in the second ones. This data showed that even though it was the second time he met his therapist, Bertie found it so difficult to speak and stammer in some occasions.

Bertie : "Besides, y-you..you tricked me!"

Bertie : "I-I'm willing to work hard, Doctor Logue...."

Bertie : "Are you....are you... are you willing to do your part?"

Lionel : "All that's about a shilling's worth." 
Bertie : "(Angry) Forget about the blessed shilling! (Calm again) Perhaps, upon occasions... you might be requested to assist... in coping with... with some minor event. Would that be agreeable?"

In the dialogue, consonant adding appeared as usual (the sound "i i") but the repeated sound became worst. If in the previous dialogue he only repeated one word, in this current dialogue he repeated two words and it happened three times; "Are you... are you... are you". There is an interesting fact about his speech, the underlying sentence, "Forget about the blessed shilling!" is the evidence that he actually can say a fluent sentence but only when he is mad.

\section{Repeating words 'the/'he' and consonants added 'f'/'m'/'g'/'p'/'c' and 'k'}

Speech disorder can be worse if it is triggered by bad emotional involvement. The data below proved that Bertie's speech disorder became worse when he was in a bad mood situation. This conversation occurred when Bertie came to his therapist after his father's funeral.

Bertie : "I was informed, after the..t-the fact that my father's... my father's last words were "Bertie has... m-more... g-guts than the rest of his brothers... p-put together". Hhhh (Smile)....He couldn't say that to my face. My brother."

Lionel : "Sing me the chorus."

Bertie : "No. Certainly not. (Look at the un-fixes airplane model in the table in front of him) You know... I always wanted to build models. But... father wouldn't allow it. He... H-He collected stamps. So we had to collect stamps." (Take one of the airplane model)

Bertie : "I'm not... c-c... c-crooning "Swanee River".

Bertie : "To tell the truth, it was a relief...Knowing I... wouldn't be... k k... king."

Lionel : "But unless he produces an heir, you're next in line. And your daughter, Elizabeth, would then succeed you."

Bertie : "You're barking up the wrong tree now, Doctor, Doctor."

Like the previous dialogues, this also contains stuttering signs like repeated words "the" and "he", and more consonant sounds adding such as "t", "m", “g”, “p”, "c", and "k". All of the signs in this data indicated that Bertie's speech disorder was getting worse when his emotional feeling is bad. This situation was triggered by the death of his father. His bad feeling caused him to stammer more often than of the normal situation.

\subsubsection{Muteness}

This conversation occurred when Bertie comes to his therapist after his father's funeral. Here, Bertie's speech disorder became worst during his bad emotional feeling. It also confirmed that speech disorder in the form of muteness was also happening when Bertie was in a bad mood situation. 
Lionel : "What about him?"

Bertie : : "...." (Try to say something but failed)

Lionel : "Try singing it."

Muteness also happened in another occasion when Bertie met his old brother and were debating after their father's death. In this dialogue, Bertie was muted twice by no reason. Bertie became hard to speak even when he was speaking with his own brother.

Bertie : "I'm trying to..." (Try to say something but failed and then silent)

David : "Yearning for a larger audience are we, B-B-B-B-Bertie?"

Bertie : "Don't..." (silent).

Even though repeated words and added consonants did not appear in this dialogue, pauses mode always appeared as usual as a clear characteristic of disfluency and speech disorder. From all of the data presented above, I concluded that Bertie or King George VI's language productivity was really bad because he had speech disorderproblems affected his ability to speak. The first speech disorder form was disfluency which were clearly seen along the dialogues. The characteristics of disfluency that existed in the movie were pauses mode, repeated words, added extra sounds (meaningless ones), produced long voices and showed visible frustration expression when he wanted to speak. Almost all of the characteristics of stammering were revealed in Bertie's speech or utterances. In addition, articulation disorder also appeared in some of the dialogues. It was obviously apparent in the way he added unnecessary consonant sounds when he was speaking. And the most often usedconsonant sound added to his words was when he said the wordwith " $\mathrm{K}$ " in the beginning. It was hard for him to say it fluently and smoothly. The last was muteness. This kind of speech disorder appeared especially when Bertie was having a bad feeling or mood. However, in some rare occasion, Bertie could speak fluently despite of his bad feeling or emotional disturbance, such as when he was in anger.

\subsection{The Strategies of Speech-Language Therapy Given to King George VI}

From the data, we know that King George VI had several speech disorders. They were disfluency, articulation disorder and muteness. Untreated speech disorders may cause a person to experience a great deal of anxiety when talking to people. Over time, this anxiety can trigger anxiety disorders or a phobia of speaking in public. Early treatment for anxiety can help to prevent the development of anxiety disorders. In the movie, Lionel was the therapist who cured the king's speech disorders. He gave some treatments and exercises to overcome and reduce the king's speech disorder problems. Below are the detail strategies used by Lionel to help the king cured his speech disorders. 


\subsubsection{Muscles Strengthening Exercises}

As the therapist, Lionel gave Bertie breathing and muscles strengthening exercises to cure his speech disorder problems.

Lionel : "Alright. You want mechanics? We need to relax your jaw muscles and strengthen your tongue by repeating tongue twisters. For example, "I am a thistle-sifter. I have a sieve of sifted thistles and a sieve of unsifted thistles. Because I am a thistle sifter."

Relaxing jaw muscles and strengthening tongue is one of the ways to do muscle strengthening exercise. As stated on the script, Lionel has a unique form of sentences to strengthen the tongue muscles by saying the string of these words "I am a thistle-sifter. I have a sieve of sifted thistles and a sieve of unsifted thistles. Because I am a thistle sifter." The sentences contain a lot of words begin with "th" and "s". Those two syllables in Phonology are related with the role of our tongue to produce sounds. The "th" sound in phonology is categorized as 'dental fricative', while "s" sound in phonology is an 'alveolar fricative'.Lionel recognized that by saying those sentences repeatedly, he hoped that the king's speech disorder could finallybe reduced and solved.

\subsubsection{Breath Strengthening Exercises}

As the therapist, Lionel gave Bertie an exercise to strengthen his breathing. The scene in the movie showed that Bertie could not control his breathing due to his nervousness. So, this kind of exercise would help Bertie to be able to control his breathing while speaking.

Lionel : "And you do have a flabby tummy. So, we'll need to spend some time strengthening your diaphragm. Simple mechanism."

As stated in the script, the word 'diaphragm' is an organ in our body that relates to breathing matters. It is part of the body thatcontrols our breathing. In Phonetics, some words need an extra breathing to produce some difficult consonant or vowel sounds. Hence, Bertie needs this treatment to overcome his breathing problem and nervousness.

\subsubsection{Phonetic Therapy}

Lionel realized that Bertie had some difficulties in saying some consonants such as " $t$ ", "m", "g", "p", "c" and often failed in saying the words begun with consonant "k". To solve this problem,in one of his therapy sessions Lionel gave Bertie some phonetic exercises.

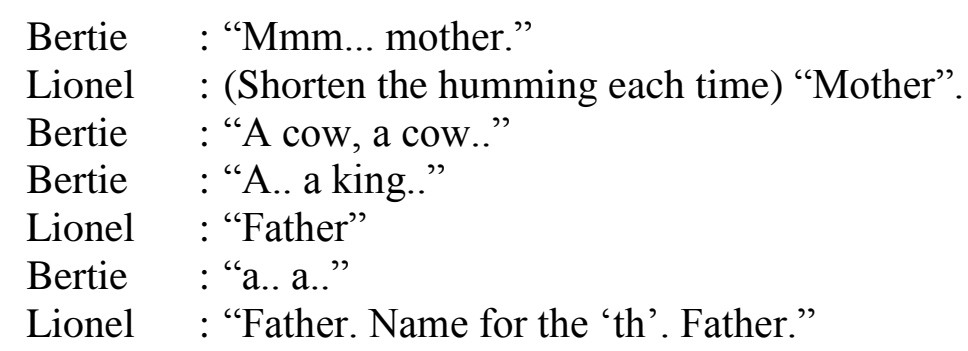


Bertie : "Father."

Not only that, the second data below also proved that phonetic therapy was important to be given to Bertie. Bertie needed more phonetic therapy to make him accustomed to moving his tongue when saying some difficult consonant sounds.

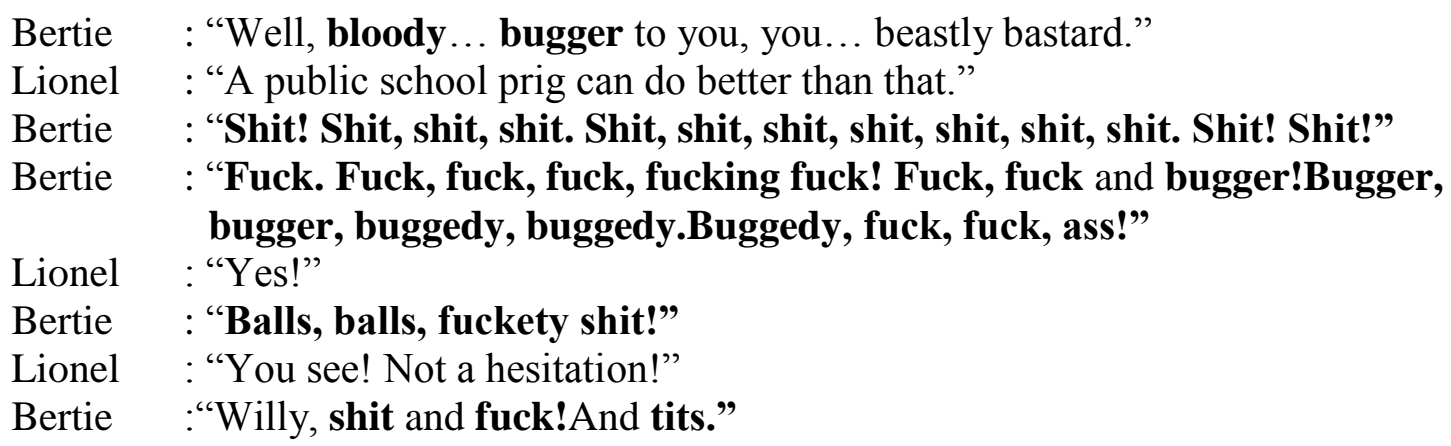

As Lionel found that Bertie did not stutter when swearing, so in that therapy session, Lionel ordered Bertie to say some swearing words. Especially the words with consonant " $\mathbf{f}$ ", as we know in phonology it is categorized as 'labiodental'. Based on the first and second data, Lionel gave language therapy related to phonetic syllables. This phonetic matter was appropriate for speech therapy treatments.

\subsection{The Process of Speech-Language Therapy Given to King George VI}

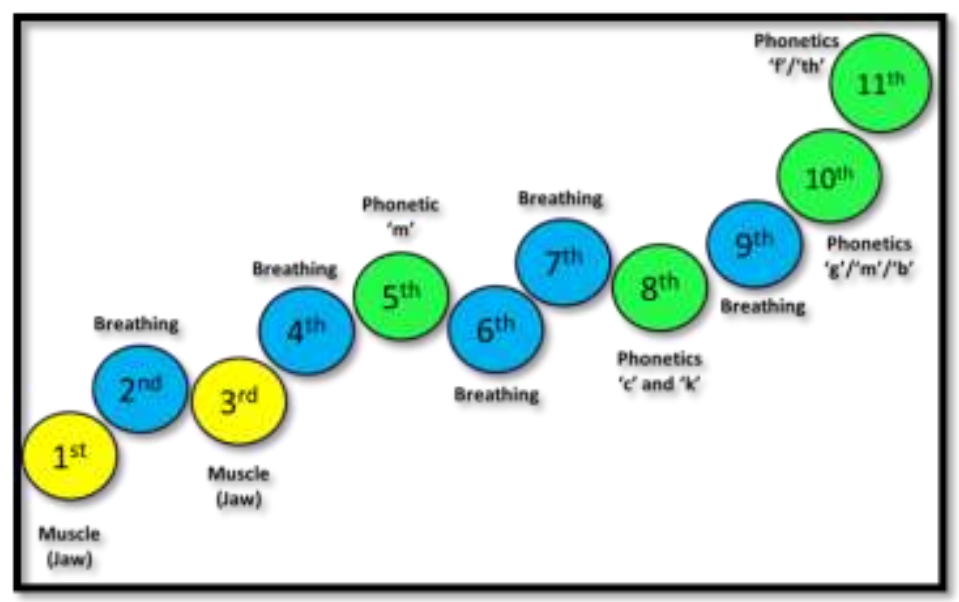

Figure 1. Steps of Speech-Language Therapy

\subsubsection{Jaw Muscle Strengthening Exercises}

As seen in the movie, there were two treatments given to the king in the first and third session of his therapy. These kinds of therapy were given to strengthen the muscles in the mouth.

Bertie : "Ayayyayaayyayayaa...." (While shaking hands)

Lionel : "Feel the loosens of the jaws" 
When saying "ayayayayya" the mouth will be open, moving up and down. Such treatment could make the king's muscles relax, especially those in his jaws and throat.

\subsubsection{Breathing Strengthening Exercises}

This kind of treatment was given in the second session of Bertie's therapy. Theexercises were designed to strengthen Bertie's breathing.

(Jumping and shaking shoulders)

Lionel: "Good. Little bounces. Loose. Shoulders loose. Shoulders loose."

One of the treatments to cure speech disorder is by doing an exercise to control breathing. In jumping, our lungs will be automatically able to control breathing. Such exercise could help Bertie to get a good perspiration when talking.

The next level of Bertie's therapy was higher and more difficult than the previous one.

(Laying on the carpet)

Lionel : "Take a nice deep breath. Expand the chest. Puts your hands onto your ribs. Deeper. Good. How do you feel?"

Bertie : "Full of hot air." (And the king's wife sit on her stomach)

Lionel : "And slowly exhale... and down comes Your royal highness."

Lione : "Loosens the shoulders. Ding dong bell, pussy's in the wall. Bertie's in the well. Who put her in?"

Bertie : "(rolling on the floor) Little Tommy Tin." (Swinging their two hands from right to left, up and down)

Lionel : "Another deep breath and Jack and Jill"

Bertie : "Jack and Jill."

Lionel : "Went up the hill"

Bertie : "Went up the hill"

The data above revealed a treatment to make the king able to control his perspiration in a smooth way. Perspiration is really important to reduce the king's articulation disorder. It has been explained previously that the king had a very bad breathing's control. Hence, he needed some appropriate exercises to overcome such problem. But not only doing exercises, Lionel also gave Bertie some interactive sentences to be responded, such as "Ding dong bell","pussy's in the wall","Bertie's in the well", and "Jack and Jill". Those sentences could make Bertie to be more responsive to Lionel's therapy.

\subsubsection{Phonetic Therapy}

\section{Produce consonant ' $m$ '} "m".

The phonetic therapy starts in the fifth session of the therapy by saying the consonant

Bertie : "Mmm... mother."

Lionel : "Shorten the humming each time. "Mother".

Bertie : "Mmmmm...." 
In phonology, the sound " $\mathbf{m}$ " is a bilabial sound. Consonant " $\mathbf{m}$ " is produced when the lips are brought together. The movement of both lips can warm up the muscles in the mouth and this can be a good start for someone to speak easily. It did not need much energy for Bertie to say this consonant, but at least it could warm up his mouth muscles. This exercise was done to promote Bertie's fluency.

\section{Produce consonants 'c'/“k'/'g'/'m'/'b'/'f'/'th'}

Lionel realized that the most difficult problem faced by Bertie was when he had to produce some consonant sounds. Therefore, in some therapy sessions, Lionel gave more attention to such therapy, which were specifically focused on producing some consonant sound smoothly and correctly.

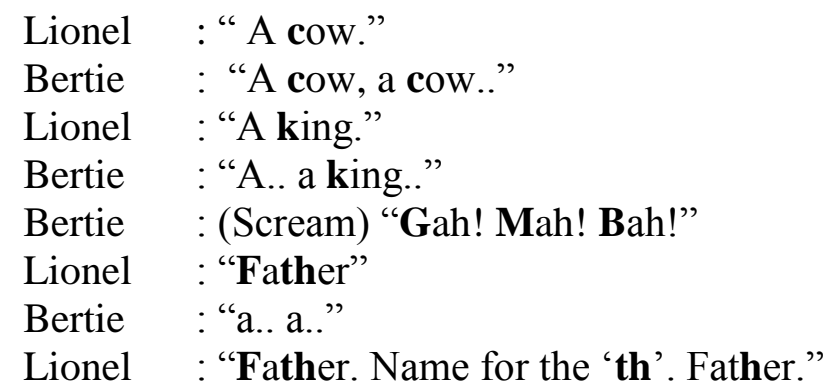

Phonetic therapy was given in many sessions (the eighth, tenth, and eleventh sessions). It was clear that Lionel paid a lot of attention to Bertie's disfluency and articulation disorder. Bertie had difficulties in saying particular words started with sound "k". So, in this therapy session, Lionel gave more training and exercises for the king so that he would get used to producing difficult consonants such as sound "c" in the "cow", "k" in the "king", consonant "f" and syllable "th" in the "father", and "g" in "gah", "m" in "mah", "b" in "bah". This exercise was intended to help Bertie to be more familiar and easier to produce bilabial sounds.

\section{Practice consonants 'b'/'s'/'f' and 't' through swear words}

The last session of Bertie's therapy was the unexpected one. The therapy occurred when Bertie came to see Lionel to share his bad feeling about his brother. Bertie's anger made him say some swearing words fluently without any hesitation. It was really unpredictable moment, both for Bertie and also for Lionel. Knowing this situation, Lionel used this 'precious' moment to continue his phonetic therapy with Bertie in unique and more spontaneous way.

\footnotetext{
Bertie : "Bugger off!"

Lionel : "Is that the best you can do?"

Bertie : "Well, bloody ... bugger to you, you... beastly bastard."

Lionel : "A public school prig can do better than that."

Bertie : "Shit! Shit, shit, shit. Shit, shit, shit, shit, shit, shit, shit. Shit! Shit!"

Bertie : "Fuck. Fuck, fuck, fuck, fucking fuck! Fuck, fuck and bugger!Bugger, bugger, buggedy, buggedy.Buggedy, fuck, fuck, ass!"
} 
Lionel : "Yes!"

Bertie : "Balls, balls, fuckety shit!"

Lionel : "You see! Not a hesitation!"

Bertie : "Willy, shit and fuck!And tits."

From the script above, we can see that the swear words uttered by Bertie containedsome of the important consonant sounds that Bertie felt as a burden. Such as "b" in the words "bugger", "bloody", "buggedy" and "balls"; "s" in the word "shit"; "f" in the word "fuck"; and consonant " $t$ " in the word "tits".

Phonetic therapy played a significant role in the king or Bertie's speech problems. And Lionel, as the Bertie's therapy, knew this very well. It seems that the set of therapy strategies followed by Bertie was paid off. He could finally produce some words that were previously impossible for him to say.

\section{CONCLUSION}

This research is about speech-language therapy given to King George VI in 'The King's Speech' movie. It is about a man with higher status but unfortunately has some speech disorders such as disfluency, articulation disorder and muteness. To overcome these problems, he met a speech therapist, named Lionel, to help him cure his problem. Lionel gave King George VI some treatments and exercises such as muscle strengthening exercises, breathing strengthening exercises and phonetic therapy. After some efforts and discipline of the king, he finally made it. In his last king's speech, he successfully read the speech until the end. In addition, he was able to reduce his stuttering, control his frequent pauses, and add no more consonants. He was also able to control his short breathing while speaking. He was no longer nervous and mute during his speech in public. Subsequently, he could interact with people and create a better social life. And as a king, his pride increased more and more after he succeeded in overcoming his speech disorder.

It is expected that this study can inspire and help the next researcher who has interest in Psycholinguistics studies, especially, those related to speech disorders. The findings that I obtain in this study is not only applicable for academic paper but also useful for real life use. It means if the treatment is properly applied, it can be used to help people with speech disorder problems. I also suggest the next researcher to analyze speech disorders using experimental approach to see to what extent the techniques can help treat people with speech disorders. 


\section{REFERENCES}

Aitchison, J. (2008). The Articulate Mammal: An Introduction to Psycholinguistics. London: Routledge.

Caplan, D. (1992). Language: Structure, Processing, and Disorders Issues in the Biology of Language and Cognition. London: MIT Press.

Damico, J. \& Martin, B. (2010). The Handbook of Language and Speech Disorders. UK: Blackwell Publishing

Field, J. (2004). Psycholinguistics: The Key Concepts. London: Routledge.

Frenandez, E. M. \& Smith, H. C. (2011). Fundamentals of Psycholinguistics. UK: Blackwell Publishing.

Kahn, A. (2016) Speech Disorder. Retrieved at 18 August 2016 from http://www.healthline.com/health/speech-disorders

Litosseliti, L. (2010). Research Methods in Linguistics. London \& New York: Continuum International Publishing Group. 